\title{
Accessible Mathematics for People with Hearing Loss at Colleges and Universities
}

\author{
J. Tilak Ratnanather
}

Communicated by Steven J. Miller

\section{Note: The opinions expressed here are not necessarily those of Notices. Responses on the Notices webpage are invited.}

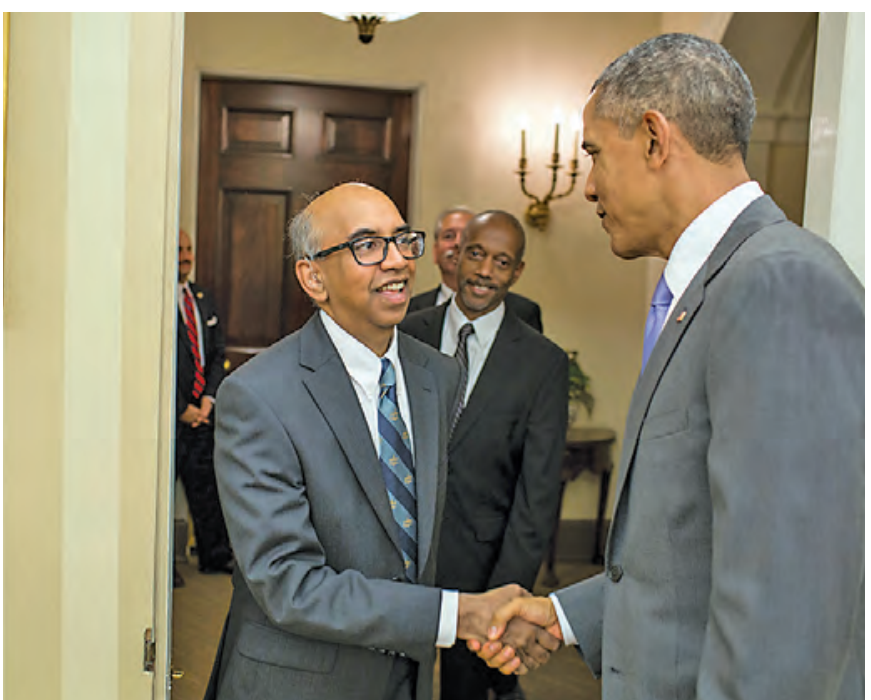

President Obama congratulates Ratnanather on the Presidential Award for Excellence in Science, Mathematics, and Engineering Mentoring

Tilak Ratnanather is associate research professor of biomedical engineering and is affiliated with the Center for Imaging Science and Institute for Computational Medicine at Johns Hopkins University. His e-mail address is tilak@cis.jhu.edu.

For permission to reprint this article, please contact: reprint-permission@ams.org.

DOI: http://dx.doi.org/10.1090/noti1588

\section{Introduction: Succeed in mathematics with hearing loss}

"Mathematics is the one subject in school that does not require hearing," wrote the late Dame Kathleen Ollerenshaw (Figure 1) [3]. She was the second person with hearing loss to obtain a doctoral degree in mathematics, at the University of Oxford in 1945. Among other things, she studied magic squares, including finding the first general solution for restoring the Rubik's ${ }^{\circledR}$ Cube. Ollerenshaw's striking statement portrays mathematics as a visual discipline that is naturally attractive to people with hearing loss. Yet few others with hearing loss have obtained doctoral degrees in mathematics. There were 13 in the United States from 2006 to 2010 [5], and at least 6 from the University of Oxford based on anecdotal information. It is remarkable that the first two were women. The

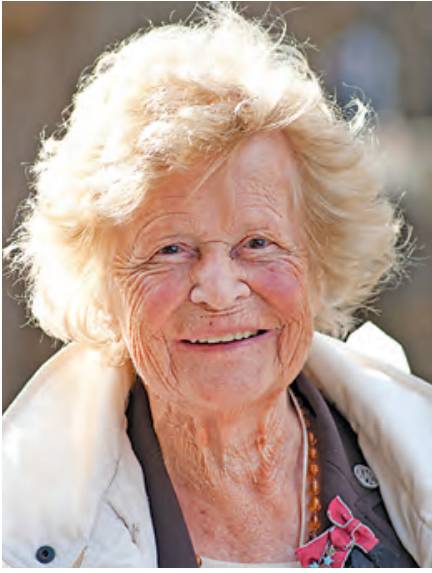

Figure 1. Dame Kathleen Ollerenshaw, the second person with hearing loss to obtain a doctoral degree in mathematics, wrote, "Mathematics is the one subject in school that does not require hearing." 


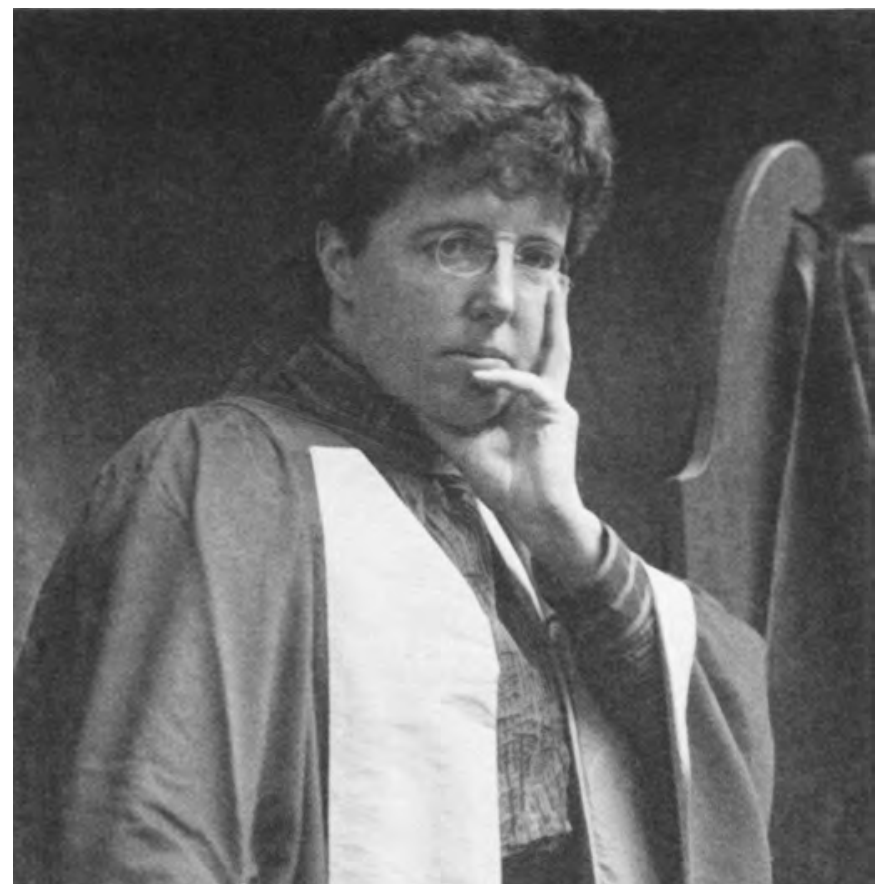

Figure 2. Charlotte Agnas Scott, the first person with hearing loss to obtain a doctoral degree in mathematics, headed the mathematics department at Bryn Mawr College, where she researched algebraic geometry and was a co-founder of the American Mathematical Society.

first was Charlotte Angas Scott (Figure 2) [2], who in 1880 was denied Eighth Wrangler ranking in the Cambridge Mathematical Tripos because she was female, but in 1885 obtained a DSc from the University of London, ironically for research at Cambridge. Scott became the first woman to head a mathematics department, at Bryn Mawr College, where she researched algebraic geometry and was a cofounder of the American Mathematical Society.

With the emergence of amplification technologies such as hearing aids and cochlear implants and accessibility legislation in some countries, more people with hearing loss are studying mathematics or using it in their teaching or research. While not all remain in mathematics, some go on to hold leadership positions in STEM (Science, Technology, Engineering, and Mathematics). One example is Vint Cerf (Figure 3), known as the Father of the Internet, who obtained an undergraduate degree in mathematics at Stanford University before pursuing his seminal doctoral research in computer science at UCLA. Another is Dimitri Kanevsky (Figure 4), who obtained a $\mathrm{PhD}$ in mathematics at Moscow State University before moving to the United States, where he carved out a productive career in speech recognition, first at IBM Research and now at Google. As these achievements indicate the potential for people with hearing loss to "focus on [their] strengths and talents"1 in acquiring mathematical knowledge, it is opportune to

$\sqrt[1]{\text { obamawhitehouse.archives.gov/realitycheck/ }}$ blog/2012/05/07/technology-change-great-equalizer.

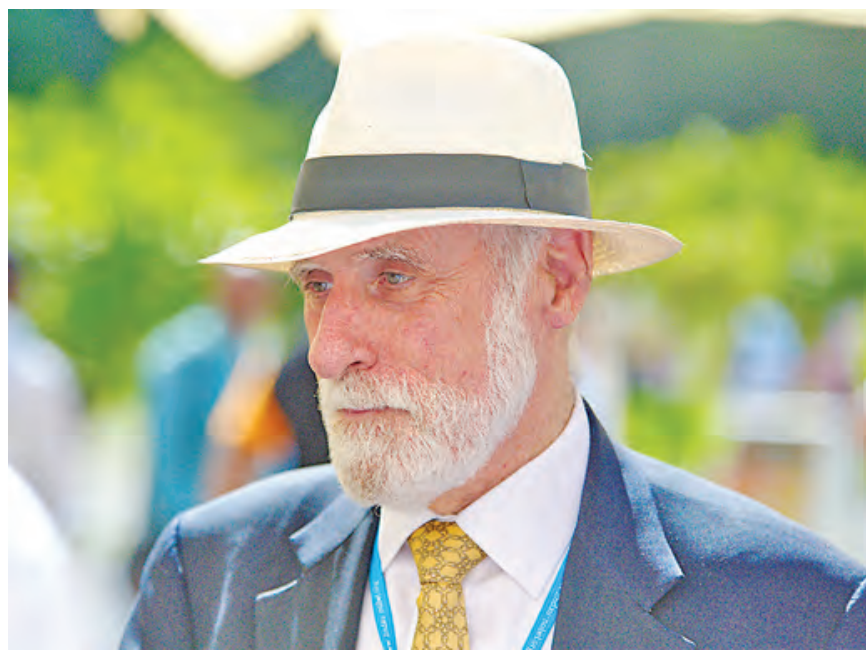

Figure 3. Vint Cerf, "Father of the Internet."

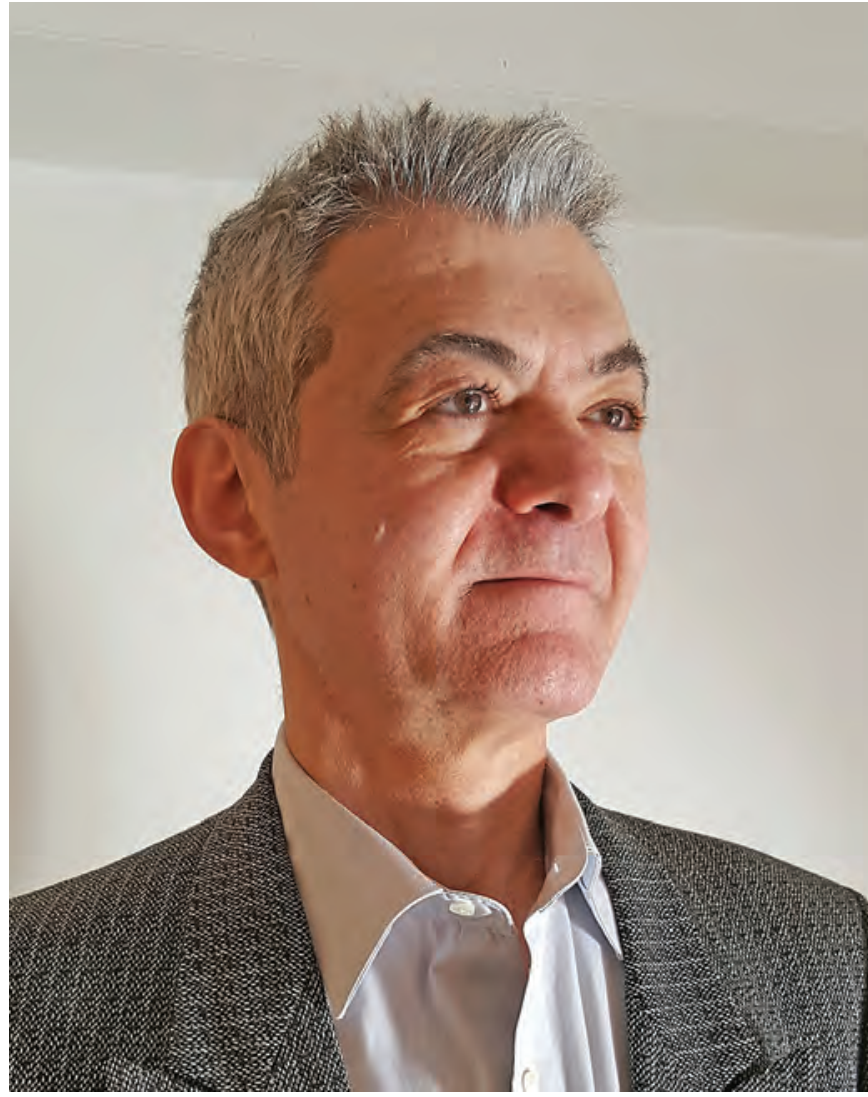

Figure 4. Dimitri Kanevsky advanced speech recognition, first at IBM Research and now at Google.

describe how mathematics can be made more accessible at colleges and universities.

\section{Hearing loss: Underrepresented in STEM}

Hearing loss cuts across society. According to the World Health Organization, hearing loss with auditory threshold elevations greater than $40 \mathrm{~dB}$ in the better ear has a global incidence of five percent. People with hearing loss struggle with reduced access to auditory information 
and have to deal with the societal challenges of isolation, ignorance, and invisibility. In the United States, the proportion of people in STEM with hearing loss is extremely small, only about one percent [5], partially due to low proportion among college students-those with hearing loss are estimated to number from 30,000 to 400,000, representing 0.3-4.0 percent of all college students. Hearing loss covers two broad spectra. First, the degree ranges from partial (which can be corrected with hearing aids) to profound (which in some cases can be mitigated with cochlear implants). Second, hearing loss can be congenital, progressive, or acquired. For example, Scott's hearing loss was acquired in childhood and became progressively profound while Ollerenshaw's was congenitally partial and then progressively profound. People with hearing loss hear sounds across a limited frequency range regardless of loudness, have trouble distinguishing speech in noise, and find it difficult to interpret speech from a sparse signal. As amplification elevates both speech and background noise, articulation becomes important. Therefore accessibility to mathematics for people with hearing loss at college and university must be in the context of their needs.

\section{Accessibility: Small steps, but leaps for mankind}

In the United States, 2,500-3,000 college students with hearing loss attend specialist tertiary institutions, where they receive a whole range of support services such as sign language interpreters, lipspeakers, and captioning [1]. But support services at mainstream colleges attended by the other 96-99 percent of college students with hearing loss vary in terms of depth and coverage [3]. Further, professors with hearing loss, who number in the hundreds worldwide, experience a different set of problems [4]. Both groups have common accessibility needs.

The acoustic environment is important. Ambient noises such as traffic, people walking and talking, moving furniture, rustling paper, and air conditioning can be difficult to filter out while focusing on speech in conversations, lectures, and seminars. Soundproofing such as carpeting and low ceilings helps to mitigate effects of reverberations, while offices with an open plan are disastrous. Clear speech should be encouraged: carefully enunciated words can go a long way to maximize learning and the distillation of essential points. So can concise, clear presentations. Good lighting, balanced between the speaker's face and the projector screen, also helps. Above all, interactive whiteboards, blackboards, and flip charts facilitate twoway communication. All of this applies not only in classroom lectures, but also in seminars and podium talks at conferences and workshops.

Technology can help. If amplification is used, clear speech can be enhanced by assistive listening devices, such as inductive loop, FM, WiFi, and infrared systems. I vividly recall the clarity of a university lecturer using an FM system; there were a few occasions when I anticipated what was going to be said. This is clearly a cognitive benefit of the six dB gain provided by these devices. Nowadays with group discussions and the proliferation of the flipped classroom, it is common to be seated around a table. Here a flip chart and a sound field system help, especially if pauses are taken before speaking with a microphone. Online lecture notes help, especially when accompanied by write-ups by note-takers who pick up the interesting digressions.

Real-time captioning is now available on-site or remotely. A transcriber receives the speech signal and converts it to text. Technical words can be communicated in advance to the captioner for assembling a dictionary that deepens over time. With rapid advances in hardware and software, captioning and speech-to-text tablet applications will help to level the playing field in the years to come. Interactive content produced by captioned MOOCs has an enormous potential to facilitate learning and teaching by everyone and provide more time for personal contact.

\section{Strategies: Thinking outside the box}

Hearing loss is personal, so what works for one may not work for another. Thinking outside the box can yield solutions to the benefit of all. Ian Shipsey, professor of experimental physics at the University of Oxford, goes to "extraordinary lengths to make [his] explanations clear so that the questions [from his students] would not be trivial ones."2 As a student, David James, now professor of mathematics at Howard University, found that "mistakes [were] productive; when [he] made one, the teacher could explain exactly why it was wrong and [he] could learn from that." ${ }^{3}$ In algebraic manipulations, it might be better to use phonetically distinct symbols. Only when I got my cochlear implant a few years ago was I able to differentiate the articulation of $\varphi$ and $v$ as the diffeomorphism and velocity associated with geodesics in shape spaces in computational anatomy. To deal with questions in a large room, Scott and Ollerenshaw were assisted by graduate students in classes [2] and hosts at seminars [3]; in my case, moderators at conferences have been helpful.

People with hearing loss often experience greater visual acuity. This may explain why people with hearing loss think differently, as in Ollerenshaw's use of subluminal thinking to solve problems [3] and Scott's preference for geometrical reasoning based on simple but rigorous proofs [2].

\section{Summary: Mind that person who may have hearing loss}

Making mathematics more accessible to people with hearing loss in colleges and universities should significantly improve the underrepresentation of people with hearing loss in STEM. In particular, enhanced ac-

4www.sciencemag.org/careers/2010/04/profiles-techno1ogica1-adaptation

${ }^{3}$ from The Voices of the Oral Deaf: Fourteen Role Models Speak Out by J. Reisler 
cessibility will go a long way to address the societal challenges of hearing loss. By far the two biggest challenges are invisibility and isolation, which cause hearing loss to be underreported. Though I was motivated, I knew only a few people with hearing loss who had succeeded in mathematics, so I had some doubts. Such doubts can be dispelled by knowing about and networking with mathematicians with hearing loss. The third challenge is ignorance due to lack of information about dealing with hearing loss, so it is important to self-advocate for accessibility. Having more people with hearing loss in mathematics, aided by advances in amplification and pedagogy, has the potential for new ideas and concepts in mathematics to emerge to the benefit of everyone.

ACKNOWLEDGMENT. I thank my mentors at University College London and University of Oxford, and fellow mathematicians too numerous to mention here for their support throughout my career.

\section{References}

[1] H. ADLER, B. JACOB, K. KuRZ, and R. KuSHALnAGAR, Undergraduate research in mathematics with deaf and hard-of-hearing students: four perspectives, Involve, a Journal of Mathematics 7 (2014), 247-264.

[2] P. C. Kenschaft, Charlotte Angas Scott, Women of Mathematics: A Biobibliographic Sourcebook, L. Grinstein and P. Campbell, ed., Greenwood Press, 1987.

[3] K. Ollerenshaw, To Talk of Many Things: An Autobiography, Manchester University Press, 2004.

[4] D. H. Smith and J. F. ANDREwS, Deaf and hard of hearing faculty in higher education: enhancing access, equity, policy, and practice, Disabil. Soc. 30 (2015), 1521-1536.

[5] C. M. Solomon, D. Braun, R. Kushalnagar, R. E. LADneR, D. LUNDBERG, R. PAINTER, and R. NUZzO, Workshop for emerging deaf and hard of hearing scientists (2012), www. washington. edu/accesscomputing/WhitePaper-Final_Ca11audet_ emerging_sci_2_15_13.pdf/.

Photo Credits

Photo of Ratnanather and President Obama courtesy of Pete Souza.

Figure 1 courtesy of Somerville College Archives, Oxford.

Figure 2 courtesy of Special Collections Department, Bryn Mawr College Library.

Figure 3 courtesy of Peter Badge.

Figure 4 courtesy of Dimitri Kanevsky.

Photo of Tilak Ratnanather courtesy of Will Kirk, Johns Hopkins University.

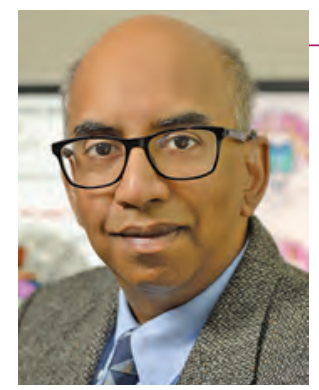

\section{ABOUT THE AUTHOR}

Born with profound bilateral hearing loss, Tilak Ratnanather has recruited or mentored more than 50 individuals with hearing loss worldwide in science, technology, engineering, and mathematics.
American Mathematical Society
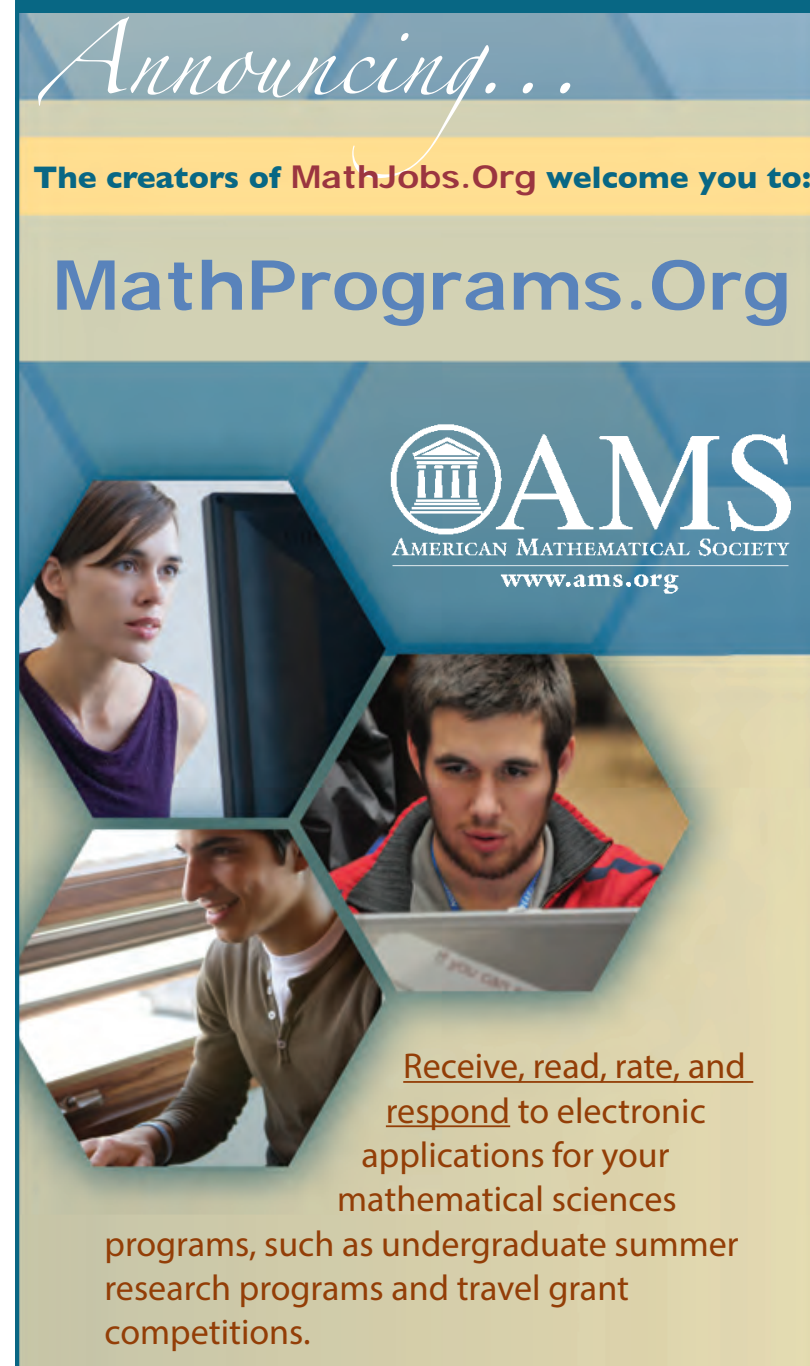

Customize your settings and control the application form; also set secure access for the admissions committee.

Enter program announcements for public display.

Download data to personal computers for use in word processing and spreadsheets or as a full permanent storage file.

\section{Service is FREE to applicants.}

Institutions pay annually for one program or for multiple programs. 